\title{
La Invención de Morel: Lectura y Lectores
}

En la literatura hispanoamericana contemporánea hay obras que dificultan una lectura no crítica. Son obras que percenecen a una tradición de novela autorreflexiva, no sólo temáticamente sino en su estructura, que incluye textos en los cuales la articulación de los elementos que crean el efecto de ruptura con una realidad ajena al texto varía y señala diferencias. De esta forma se puede hablar de obras que permiten una lectura ingenua además de una lectura crítica y otras en las que la maquinaria de su ejecución está tan al descubierto que la ilusión de ser reflejo de una realidad exterior, la posibilidad de una lectura ingenua, queda anulada. ${ }^{1}$ Estos texíos se proponen como producción en los

${ }^{1}$ Al presentar una lectura de El obsceno pájaro de la noche Alicia Borinsky hace este planteamiento ( $M L N$, Hispanic Issue, 1972), que repite en una ponencia que leyó en el Congreso de Literatura Iberoamericana realizado en Michigan durante el mes de agosto de 1973. La ponencia gira en torno a la novela de Bioy Casazes publicada en 1945, Plan de evasión, y se titula "Plan de evasión de A. Bioy Casares: la representación de la representación". En ella dice:

Resulta difícil pensar cómo sería una leçura "ingenua" de Plan de evasión. La noveia elude prolijamente la tentación acrítica: sus personajes carecen de caracterización psicológica que permite mecanismos de proyección en el lector, su argumento - si aún encontramos valor en esa palabra - es verticalmente inexistente o, en todo caso, es el tejido de desconfianzas y sospechas que organiza la obra. Este tejido está diseñado para romper la confianza en la representación.

Alfred J. MacAdam durante el mismo Congreso presencó una lecîura de La invención de Morel en la que se sitúa dentro del marco de esća misma problemática. Nota cómo el discurso de esta novela funciona como metáfora del texto. (Véase textos en Otros mundos, otros fuegos...XVI Congreso del Instituto Interaacional de Literatura Iberoamericana (ed.|Donald A. Yates, Pittsburgh, 1975).

Ano María Barrenechèa en su estudio sobre la literašura fantástica ( La literatura fantástica en Argenîina, México, Imprenta Universitaria, 1957) parte de diferente planteamiento. Al hacer una lectura del libro de Todorov, Introduction à la litterature fantastique ("Ensayo de una topología de la literatura fantástica", Revista Iberoamericana, $N^{\circ} 80$, julio-septiembre 1972, pp. 391-403) y diferir en algunas de las conclusiones del texto, no se separa de la tesis que utiliza Todorov como punto de partida. Esta es: "que la literatura fantástica debe tener como soporte indispensable un arte represent́ativo, puesto que si la hemos basado en elcontraste de hechos anormales y normales, necesita ser representativo de esos hechos." Dentro de mi planteamiento sería una contradicción estudiar lo fantástico a trávés de una relación del discurso con un referente sino más bien habría que considerarlo como cierto efecto de la articulación del discurso.

Este tipo de lectura es sugerida por un texto como "The Uncanny" de Freud. 
cuales el discurso se articula de forma que se eliminen los mecanismos que crean la ilusión de profundidad de la literatura realista o sea, el efecto del texto como espejo de algo fuera de él.

El discurso de Adolfo Bioy Casares ${ }^{2}$ se coloca dentro de esta problemática y ofrece textos que imposibilitan la lectura no crítica. A través de desdoblamientos en su discurso podemos movernos dentro del texto y percibir su realidad. Discurso que contiene al reflejo y lo reflejado, que se presenta como metáfora del texto. ${ }^{3}$

Asombra que el invento naya engañado al inventor. Yo también creí que las imágenes vivían; pero nuestra situación no era la misma: Morel había imaginado todo; había presenciado y había conducido el desarrollo de su obra; yo la enfrenté concluida. (122) ${ }^{4}$

Borges en el prólogo que acompaña a La invención de Morel califica la "trama" de perfecta. Critica a la "novela psicológica" por ser "informe" y porque "prefiere que olvidemos su carácter de artificio verbal y hace de toda vana precisión (o de toda lánguida vaguedad) un nuevo toque verosímil". ${ }^{5}$ En cambio encuentra que la novela de "aventuras" "no se propone como una transcripción de la realidad" sino como "objeto artificial que no sugiere ninguna parte injustificada."

La invención de Morel nos enfrenta al discurso en primera persona de un fugitivo que llega a una isla y encuentra que, tal como le han advertido, una peste ha culminado con la muerte de todos los habitantes. Sin embargo, antes de desaparecer, una semana de la vida de las víctimas fue grabada por la máquina de Morel incluyendo a Morel mismo. Por lo tanto lo que encuentra el fugitivo es una proyección sobre el escenario de la isla. Se enamora de una de las "imágenes" proyectadas y resuelve grabar la suya que, a través de diferentes montajes, une a la de su amada. Ya la peste, que no es más que el resultado de ser grabado, está consumiendo su cuerpo.

La novela es una novela de aventuras. El fugitivo ha decidido escribir un diario en el cual relata los acontecimientos que se le presentan; "cuenta" sus aventuras. Pero la isla no es una isla corriente sino el escenario de la invención de Morel, máquina que repite. con un nuevo tipo de película, lo que ella grabó. Morel la explica en su manuscrito:

2 Ofelia Kovacci es autora de la introducción más amplia a la obra de Bioy Casares (Ediciones Culturales Argentinas, Buenos Aires, 1963). Está integrada por un esbozo biográfico, algunos rasgos generales de la obra y la bibliografía más completa hasta 1963. Un segundo estudio de interés es el prólogo de Enrique Pezzoni a una antología de la obra de Bioy editada por él, (Adversos milagros, relatos. Prólogo y selección de E. Pezzoni, Monte Avila Editores, Venezuela, 1969).

3 Alfred Mac Adam en la ponencia presentada en el Congreso de Literatura Iberoamericana (Michigan, 1973) señaló el gesto altamente autorreflexivo de La invención de Morel.

4 La paginación corresponde a: Adolfo Bioy Casares, La invención de Morel, (Buenos Aires, Emecé Editores, 1970).

5 Jorge Luis Borges, "Prólogo" La invención de Morel de Adolfo Biov Casares (Buenos Aires: Emecé Editores) p. 12. 
Esta isla, con sus edificios, es nuestro paraíso privado... Aquí estaremos eternamente-aunque mañana nos vayamos-repitiendo consecutivamente los momentos de la semana y sin poder salir nunca de la conciencia que tuvimos en cada uno de ellos ...porque no habrá otros recuerdos en cada momento de la proyección que los habidos en el correspondiente de la grabación, y porque el futuro, muchas veces dejado atrás, mantendrá siempre sus atributos. (115)

El manuscrito aparece hacia el final de la novela y subraya lo que se ha descubierto a través del texto, esto es: que las aventuras del fugitivo no han sido sus aventuras. ${ }^{6}$ Aquí nadie lo persigue a pesar de que él está constantemente atemorizado. Aquí él es un mero espectador que reproduce en su discurso los movimientos que está presenciando; un movimiento sin desarrollo, estático, pues es el movimiento de la repetición de los siete días grabados en la máquina y por la máquina. Visto de esta forma las "aventuras" que aparecen en el diario del fugitivo son una lectura de la invención de Morel. ${ }^{7} \mathrm{El}$ mismo nos dice que su informe no tiene otro propósito que salvar las imágenes grabadas.

Un tex to consciente de su realidad como metáfora. Un discurso que se niega constantemente, en el cual no hay una voz privilegiada, y que únicamente postula alternativas. "Imágenes" cuya sola existencia es en función de su discurso y del discurso de las otras. Una trama que resulta de la negación de alternativas y que finaliza cerrándose sobre sí misma pues lo que hemos creído un desarrollo ha sido la lectura de una repetición. De esta forma La invención de Morel imposibilita una lectura no crítica. Es un texto que recuerda el comentario de Michel Foucault a propósito de la obra de Raymond Roussel:

la obra estaría entonces construida sobre todo un andamiaje de secretos que se gobiernan unos a otros sin que ninguno de ellos tenga un valor universal o absolutamente liberador. ${ }^{8}$

La lectura del fugitivo no es la única. Notamos que hay otras lecturas: Morel lee el manuscrito de su invento, el fugitivo lee partes del manuscrito que Morel no leyó y, por último, tenemos la presencia de un Editor, lector del diario del fugitivo y también lector del manuscrito de Morel cuyas páginas el fugitivo intercaló en su diario. Su discurso, en forma de notas al calce, se quiere comentario y corrección de algunos datos en el diario.

En un discurso como el que hemos señalado, que se desdice postulando siempre nuevas alternativas, es posible notar diferentes niveles. No es un discurso que opere en un solo sentido sino en muchos, a menudo contradictorios,

6 La aventura del fugitivo. Cada "lector" tiene su propia aventura que se diluye con la lectura del texto. Así la aventura de Morel, su historia de amor con Faustine, y la aventura del Editor, su obsesión por el detalle, su afán por presentar la lectura correcta, quedan incluídas en el texto como alternativas que articulan la trama.

7 Jean Ricardou, Prnblèmes du nouveau roman, Collection "Tel Quel" (París: Edition du Seuil, 1967).

8 Michel Foucault. Raymond Roussel(Buenos Aires: Siglo Veintiuno Editores, 1973) p. 16. 
presentando fisuras por las cuales podemos apreciar este mecanismo que llamamos diálogo del discurso consigo mismo. ${ }^{9}$ En un momento dado dice el fugitivo:

...Ahora, parece que la verdadera situación no es la descrita en las páginas anteriores; que la situación que vivo no es la que yo creo vivir.'(88)

Es que el diario es una lectura y por lo tanto no puede presentarse como algo definitivo, la lectura sólo puede ser una lectura que siempre apunta hacia otra. Esta proposición relativiza todo lo anterior pero a la vez no se postula como privilegiada; de esta forma se integra este texto que se niega constantemente y en el que, al no privilegiarse ningún instante, ya sea un autor, un personaje, o uno de los discursos, se presenta el texto como terreno de alusiones sin centro donde todo se produce come efecto de la articulación de ciertos elementos.

Para discutir la lectura del fugitivo nos preguntamos cómo se desarrolla y cómo se integra al discurso total de la novela.

En la primera parte el fugitivo presencia hechos que interpreta siempre en función de su situación. En la segunda "ve" a Morel leer parte del manuscrito donde explica el funcionamiento del invento $\mathrm{y}$, por último, transcribe lo que Morel no terminó de leer:

Agregaré a continuación las páginas (de los papeles amarillos) que Morel no leyó: (114)

Al final se graba a sí mismo integrándose a la máquina y eliminando toda diferencia con ella.$^{10} \mathrm{Si}$ antes había sido la máquina la totalidad de su discurso ahora es él parte del discurso de la máquina.

La novela, el diario del fugitivo, comienza con una proposición en el presente cuyo sujeto es el lector:

Hoy en esta isla, ha ocurrido un milagro. El verano se adelantó. Continúa un discurso que introduce un "yo" dentro de su proposición con verbos como "puse", "huí", "escribo", y se crea desde el principio cierta ambigüedad con respecto a la voz que narra. ${ }^{11}$ Este detalle, que puede parecer un dato sin importancia, nos interesa al postular que el fugitivo solo es dueño de su discurso en tanto que es lector y que éste no tiene ningún privilegio sobre los otros

9 Macedonio Fernández postula esta novela que dialoga consigo misma sin apuntar fuera del texto. De su novela dice ( $M$ useo de la novela de la eterna, Centro Editor, 1967):

Ella es curiosa de lo que va a contar, lectora suya, o más bien de su narrativa.

${ }_{10}$ Se integra físicamente a la película y, si no fuera por el diario, un tercer expectador (el lector del diario) no sabría que no ha podido entrar en la conciencia de Faustine. La novela termina con una súplica:

Al hombre que, basándose en este informe, invente una máquina capaz de reunir las presencias disgregadas, haré una súplica. Búsquenos a Faustine y a mí, hágame entrar en el cielo de la conciencia de Faustine. Será un acto piadoso.

La súplica está quizá dirigida a ese posible lector de la máquina que directamente, sin conocer el diario, lea al fugitivo dentro de la conciencia de Faustine.

11 Emile Benveniste, en Problemas de lingüistica general, (Buenos Aires: Siglo XXI Editores, 1973), p. 172. 
discursos de la novela (ya sea el del manuscrito, las notas del Editor, la lectura sugerida). Contribuye a la ambigüedad el tiempo verbal en presente no definido sino como presente de la proposición que lo contiene; ambiguiedad entre el presente de la narración y el presente de lo narrado que aquí subraya su calidad de pasado al ser presente de lo ya ocurrido, el presente por definición de un diario cuya escritura se realiza después que los hechos transcurren. Es un diario que se propone como, otra cosa y que cambia. El fugitivo lo llama diario, "Con puntualidad aumento las páginas de este diario" (32), testamento, "Siento con desagrado que este papel se transforma en testamento" (22), testimonio, "Escribo esto para dejar testimonio" (17). Por último considera que su obra es el medio para salvar las imágenes de Morel:

Sería pérfido suponer-si un día llegaran a faltar las imágenes-que yo las he destruido. Al contrario: mi propósito es salvarlas, con este informe. (121)

Cuando cuenta lo que sucede a su alrededor hace hincapié en la falta de participación que él tiene y desconfía de todo lo que presencia. Su lenguaje es dudoso y con frases como "creo", "me parece", "sigo mi destino", intercala alternativas en lugar de describir hechos; cree contar sus aventuras, qué no son suyas, mientras transcurren sin darse cuenta en qué consisten definitivamente, leyendo sin saber el final y sin tener una explicación autorizada para los sucesos.

El fugitivo podría darle autoridad a su discurso si en algún momento se propusiera como lector de otro discurso. Efectivamente, el fugitivo tiene el propósito de, una vez superada esta aventura, escribir páginas más importantes. que consistirán de sus lecturas de Malthus:

Si en pocos días no muero ahogado, o luchando por mi libertad, espero escribir la "Defensa ante Sobrevivientes" y un "Elogio de Malthus."(18) Se señala otro nivel donde la voz de este discurso sería independiente de él, un autor fuera del texto con una existencia ajena a su lectura. Sin embargo, "El Elogio de Malthus" no se llega a escribir como otro texto sino que está incluido como omisión dentro del diario. En una nota el Editor explica:

...el autor se demora en una apología, elocuente y con argumentos poco nuevos, de Tomás Roberto Malthus y de su Ensayo sobre el Principio de la Población. Por razones de espacio la hemos suprimido. (N. del E.) (124)

El fugitivo no podrá escribir otras cosas pues sólo existe dentro de su discurso como voz de este discurso y desaparece en cuanto éste cesa.

Es interesante considerar que la obra que pretende escribir el fugitivo es una lectura de Malthus y que el invento de Morel, la lectura del fugitivo, depende de las profecías de Malthus:

La conservación indefinida de las almas en funcionamiento está asegurada. $\mathrm{O}$ mejor dicho: estará completamente asegurada el día que los hombres entiendan que para defender su lugar en la tierra les conviene predicar y practicar el malthusianismo. (118) 
Además tiene una hipótesis y se dedica a investigaciones que piensa continuar en la isla:

(creo que perdemos la inmortalidad porque la resistencia a la muerte no ha evolucionado; sus perfeccionamientos insisten en la primera idea rudimentaria: retener vivo todo el cuerpo. Sólo habría que buscar la conservación de lo que interesa a la conciencia) (25)

El mismo se da cuenta de la estrecha relación que tiene su idea con los experimentos de Morel:

Aplaudo la orientación que dio, sin duda inconscientemente, a sus tanteos de perpetuación del hombre: se ha limitado a conservar las sensaciones; $y$, aun equivocándose, predijo la verdad: el hombre surgirá solo. En todo esto hay que ver el triunfo de mi viejo axioma: no debe intentarse retener vivo todo el cuerpo. (122)

Entre los estantes encuentra un libro de interés por dos razones: "me pareció extraño" y "me pregunté si el capítulo "Moulin Perse" no explicaría ese molino que hay en los bajos". Todo parece ser desdoblamientos de la máquina de Morel: Malthus y sus teorías, la investigación del fugitivo sobre la inmortalidad y finalmente este librito que contribuye a la explicación de las mareas que provocan la energía necesaria para el funcionamiento de la máquina. El fugitivo explica:

Confieso que las de esta isla prefieren seguir esa explicación y no la mía.

Lecturas y escrituras dentro del texto.

Hasta ahora el fugitivo está solo. Llega a la isla y su preocupación por sobrevivir le ocupa todo el tiempo. Ofrece constantemente explicaciones para lo que le rodea:

En cambio, los árboles están enfermos; ;... Encuentro dos explicaciones: 0

bien que las yerbas estén sacando la fuerza del suelo o bien que las raíces

de los árboles hayan alcanzado la piedra. (24)

Lo único que puede hacer es justificar lo que sucede postulando dos posibilidades o sea, negando la existencia de una única explicación. Todo aparece como otra cosa: el museo que encuentra en la isla, "Lo llamo museo porque así lo llamaba el mercader italiano" (25), se nos dice que podría ser un hotel espléndido o un sanatorio.

Los otros "personajes" entran en escena y son descritos por el fugitivo de la siguiente forma:

Aquí no hay alucinaciones ni imágenes: hay hombres verdaderos, por lo

menos tan verdaderos como yo. (20)

El fugitivo niega, como Morel había previsto en su manuscrito, que lo que ve sean alucinaciones, "Ningún testigo admitirá que son imágenes" (105), pero la realidad que les otorga es en función de la suya definida simultáneamente por la relación establecida. Ningún "personaje" se quiere privilegiado con respecto a los demás. 
En su afán por presentar una situación comprensible al lector trata de analizar lo que hacen estos seres que pretenden o parecen no verlo y se pregunta si no será todo un plan para atraparlo; él, mientras tanto, se dedica a observarlos y huir de ellos:

Cuando vi la colina deshabitada temí encontrar la explicación en una celada que estuviera ya funcionando. (64) Pero me acordé incrédulo, de mi condición de fugitivo y del poder infernal de la justicia. Tal vez todo fuera una estratagema desmesurada. (66)

Otras veces se intercala en las situaciones que ocurren a su alrededor. En la página 89 del texto se desarrolla esta escena:

Volvió Morel. Hablaron un minuto. Pude oir:

-...Si yo le dijera que están registrados todos sus actos y palabras?

- No me importaría

Me pregunté si habrían descubierto mi diario. Resolví mantenerme alerta. (89)

En varias ocasiones rectifica su posición con respecto a las "imágenes" para desembocar al final, y una vez grabada la suya por la máquina, en una dependencia total:

Ya no puede suprimirse la imagen de Faustine sin que la mía desaparezca. Me alegra también depender de Haynes, Dora, Alec, Stoever, Irene, etcétera (del propio Morel!) (151)

Es frecuente en el discurso de Bioy encontrar un lenguaje que podemos llamar "del sentido común" funcionando .como máscara. Este tipo de discurso que en La invención de Morel se nota en la lectura ingenua del fugitivo y que varía en las diferentes obras se articula con un mismo mecanismo: discurso que habla de sí mismo integrado por un lenguaje claro y preciso.

En aquellos momentos en que el fugitivo, al hacer su lectura, explica cosas y situaciones notamos fácilmente que su lectura está regida por este aparente sentido común. Es un lector ingenuo obsesionado con su propia historia de la cual sabemos poco más que nada y como tal ofrece soluciones ingenuas a los que él llama "hechos sobrenaturales":

Al pasar por el hall vi un fantasma del Tratado de Belidor (94)

Sentido común, lectura ingenua, preocupación por lo verosímil:

Pensé que en una isla, en un lugar tapiado tenía que haber un tesoro; pero decidí romper la pared y entrar, porque me pareció más verosímil que hubiera, si no ametralladoras y municiones, un depósito de víveres.

Temí una invasión de fantasmas, una invasión de policías, menos verosímil. (30)

Una preocupación constante en el diario es que sea creíble y que sirva de justificación, prueba o excusa. Por esta razón su autor siempre considera las posibilidades más probables. La verosimilitud no es una preocupación fuera del discurso, no es la preocupación por la relación entre el discurso y la "realidad" sino por crear un sentido dentro del discurso. De este sentido que crea un efecto 
de verosimilitud Julia Kristeva señala:

Es verosímil todo discurso que está en relación de similitud, de iden-

tificación de reflejo con otro. ${ }^{12}$

Por lo tanto la verosimilitud funciona a un nivel interdiscursivo y en $L a$ invención de Morel es la preocupación de lectores porque sus lecturas sean creíbles. Verosimilitud que al ser de una lectura funciona sólo con respecto a otras lecturas.

$\mathrm{Al}$ leer con cuidado se pueden señalar mecanismos que hacen sospechoso este lenguaje del sentido común y lo convierten en el discruso autorreferente que hemos considerado. El fugitivo huye pero nunca lo persigue nadie. La obsesión de persecución, la actitud defensiva de este narrador, postula, en los silencios, la alternativa de que esté loco, de que tal persecución no exista.

El sueño y la vigilia se enlazan sin marcar diferencias en sus discursos. A veces los sueños resultan explicación de lo que ocurre, otras veces repiten lo que ocurre o son explicados por lo que ocurre:

En la siesta de hoy como un comentario simbólico anticipado vino este sueño: mientras jugaba un partido de croquet, supe que la acción de mi juego estaba matando a un hombre. Después yo era irremediablemente, ese hombre. (55)

Acto seguido ve su realidad como la pesadilla más atroz:

Ahora la pesadilla continúa...mi fracaso es definitivo y me pongo a contar sueños. Quiero despertar y encuentro esa resistencia que impide salir de los sueños más atroces. (55)

Un sueño que recuerda un cuento de Borges, un narrador que ve en él un "comentario simbólico". Una pesadilla que no termina y de la cual es imposible despertar. No hay ninguna diferencia entre el mecanismo de los sueños y el de la realidad; el fugitivo alterna explicando uno en relación con el otro. Otras veces será la realidad la que repita el mecanismo del sueño como algo incontrolable:

Ayer no fui a las rocas. Muchas veces me declaré que no iria hoy. A la

mitad de la tarde supe que iría. (59)

El fugitivo no toma decisiones sino que se entera de lo que va a hacer. Trata de controlar sus actos pero después de haber soñado que estaba en un manicomio, otra de las posibilidades que había planteado al principio, decide que:

No creo indispensable tomar un sueño por realidad ni la realidad por

locura. (81)

Sin embargo poco después tiene un sueño que reproduce fielmente lo que ocurre durante la vigilia:

Soñé con Faustine. El sueño era muy triste, muy emocionante. Nos despedíamos; venían a buscarla; se iba el barco. Después volvíamos a estar solos, despidiéndonos con amor. (112)

Se reproduce el mecanismo de repetición que se da en la vigilia (repetición de la

12 Julia Kristeva, "La productividad llamada texto", Comunicaciones/Lo Verosimil, (Buenos Aires: Editorial Tiempo Contemporáneo, 1972). 
película). Sueños que explican, confunden, pretenden aclarar. Sencillamente, sueños que cobran la misma realidad que el resto del discurso, que son metáforas del texto ellos mismos pues son una traducción de éste.

Ya Alicia Borinsky en su lectura de Plan de evasión, novela que guarda estrecha relación con $\mathrm{La}$ invención de Morel, ha notado esta falta de distancia entre sueño y vigilia:

Imposible distinguir entre ambos; ninguno tiene un lugar claramente privilegiado como expresión de la verdad, el mundo. El discurso que refiere sueños es idéntico al que cuenta la vigilia. ${ }^{13}$

En La invención de Morel es imposible hablar de "personaje" y "protagonista". La creación de un personaje supone una caracterización física y psicológica que, partiendo del discurso de la novela, se separa de éste y permite pensarlo como personaje. ${ }^{14} \mathrm{En}$ esta novela de Bioy el fugitivo, a quien se podría señalar como personaje-protagonista-narrador, destruye, a través de su diario, la posibilidad diluyéndose totalmente en su discurso.

$\mathrm{Y}$ más, que tengo seguridad que nadie vivo se ha entrado a la narrativa, pues personajes con fisiología, además de muy estorbados de cansancios e indisposiciones son de estética realista y nuestra estética es la inventiva. ${ }^{15}$

En una primera instancia el fugitivo se presenta como personaje al ser aparente protagonista de una trama. Sin embargo poco a poco el discurso avanza y el protagonista resulta un mero espectador separado de lo que se podría considerar la trama de la novela. Esto es si consideramos la película que se repite cada siete días como trama de la novela.

Podríamos plantear como trama a esa que se desarrolla entre el momento que llega el fugitivo a la isla hasta el momento en que decide grabar su imagen. Señalamos que la posición que ocupa el fugitivo al llegar a la isla es la de "lector" de la película que se reproduce frente a sus ojos. Al final, en cambio, decide grabarse él mismo y se convierte en parte de la película; de lector pasa a ser discurso. Al preguntar qué sucesos transcurren en esta segunda trama notamos que son los de la primera. O sea, en la segunda trama, en la que se le podría considerar protagonista, reproduce la primera trama, la película, como lector. Es autor de un diario que propone un discurso que niega la autoridad que el ser autor le otorgaría; autor de un discurso en tanto que lo escribe, pero no "dueño" de él, es decir, no es eje organizador de su discurso. Se subraya su ser lector. La máquina como un texto abierto frente a él es su lectura y el diario es la reescritura en tanto que la trama teje una sucesión de excusas para establecer relaciones entre lectores que se leen en una cadena infinita.

13 Alicia Borinsky, Congreso de Literatura Iberoamericana, Michigan, agosto 1973, ponencia sobre Plan de evasión de Bioy Casares.

14 Ibid.

15 Macedonio Fernández, Museo de la novela de la Eterna, (Buenos Aires: Centro Editor de América Latina, 1967), p. 20. 
Morel también lee y escribe. Existe solamente como "imagen" leída por el fugitivo ya que existe sólo dentro de la película. Lo privilegia, con respecto a las otras imágenes, el hecho de ser autor del manuscrito donde explica su invento. La cadena de lecturas que se desarrolla al considerar este manuscrito nos sirve para resumir el mecanismo del texto. El fugitivo ve a Morel leer su manuscrito ("leer para no cometer inexactitudes" (98)). El fugitivo nos presenta su lectura de esta lectura de Morel. Aparecen después las páginas no leídas por Morel pero que aparecen en el diario con notas del fugitivo al margen. Por último notamos una nota del propio Morel a su manuscrito que el Editor incluye:

Siempre: sobre la duración de nuestra inmortalidad: sus máquinas, simples y de materiales escogidos, son más incorruptibles que el Metro que está en París (N. de Morel) (115)

En este texto no hay discurso que no incluya su lectura. Lo que nos lleva al Editor que de alguna forma se postula como lector último, único que físicamente no se incorpora a la máquina pero cuya única existencia es la de leer el diario (que es lo mismo que leer la máquina de Morel, el manuscrito). Un editor implica una lectura posterior que se ofrece como comentario con autoridad y distancia frente al texto. Este Editor traiciona su papel presentando un lenguaje igual al del texto, dudoso, ambiguo.

Éncontrar un editor en La invención de Morel es significativo visto en la totalidad de la obra de Bioy. Es la presencia física del "lector". En Bioy es frecuente el discurso en forma de diario (La invención, El diario de la Guerra del Cerdo) o en forma de carta (Plan de evasión). En ambos casos hay implícito un lector y en algunos está presente dentro del texto como tal: en Plan de evasión las cartas de Nevers son comentadas, leídas y resumidas por otro persỏnaje, en Dormir al sol Félix Ramos es el lector del documento de Bordenave. El Editor en La invención de Morel lee, corrige, y edita. Su lectura se propone a diferente nivel que la del fugitivo pero si examinamos su discurso notamos que, en contradicción con su aparente autoridad como editor, se integra al texto como una alternativa y nada más. Está obsesionado con su carácter de mera opinión ("Lo dudo", "Ha podido no verlos?", "O será más bien...") que señala y destaca detalles irrelevantes. Su discurso en forma de interrogación provoca el efecto de sugerir la otra lectura que incluye al lector fuera del texto.

La "literature" misma, que ha llegado a la madurez que le permite escribirse también como una máquina y ya no solamente de hablar como un espejo, se enfrenta con su propio funcionamiento a través de la palabra. ${ }^{16}$

He querido presentar el discurso de este texto y mostrar en él cómo se articula el mecanismo que va de lector a lector en una máquina que funciona indefinidamente. Por lo tanto los narradores no son delineados de tal forma que se les pueda pensar como personajes sino que existen como consecuencia de la voz 
del discurso; desdoblamientos de una misma voz, la del texto. La trama es lo que resulta de estas múltiples lecturas que se entrelazan desmintiéndose. 
